\title{
The Philosophy of Language and Knowledge Organization in the 1930s: Pragmatics of Wittgenstein and Ranganathant
}

\author{
Gustavo Silva Saldanha
}

Instituto Brasileiro de Informação em Ciência e Tecnologia (IBICT), 155, Rua Lauro Muller, Botafogo 22290160 Rio de Janeiro, RJ, Brasil, <gustavosaldanha@ibict.br>

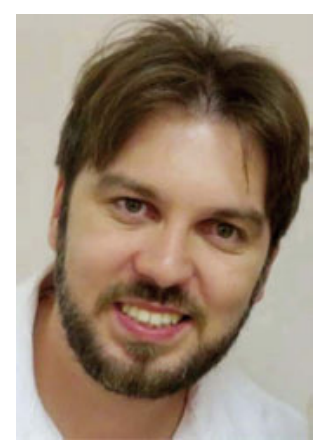

Gustavo Silva Saldanha is associate researcher at the Brazilian Institute for Information in Science and Technology (IBICT) and associate professor at the Federal University of the State of Rio de Janeiro (UNIRIO). He investigates the philosophy and epistemology of information and the basic concepts of information, documentation and bibliography. He holds a masters degree in information science from the Federal University of Minas Gerais (2008) and a Ph.D. in information science from the Brazilian Institute of Information in Science and Technology (IBICT), in partnership with the Federal University of Rio de Janeiro (UFRJ).

Saldanha, Gustavo Silva. The Philosophy of Language and Knowledge Organization in the 1930s: Pragmatics of Wittgenstein and Ranganathan. Knowledge Organization. 41(4), 296-303. 12 references.

Abstract: This paper proposes a historical-epistemological study of knowledge organization focused on the 1930s. The main question is the development of a thought-oriented pragmatics of language in the philosophical scene of the period. In distinct foci, the Austrian philosopher Wittgenstein and Indian philosopher Ranganathan discussed epistemological development under the premises of a pragmatics of language. The aim is to propose analysis of the dialogue between the visions of Ranganathan and Wittgenstein in the construction of the possibilities of knowing from the use of language within the 1930s. The method adopted is the "panoramic presentation" of Wittgenstein, based on the analysis of concepts to understand the construction of a grammar within a community of language use. As main results, we draw attention to the potential correlation between the development of the philosophy of language in the 1930s and the construction of an epistemology for the organization of ordinary knowledge. Knowledge organization needs to review recognition of the pragmatic construction throughout the twentieth century as a theoretical assumption for the understanding of a notion of knowledge from the point of view of pragmatics.

Received: 12 May 2014 Accepted: 14 May 2014

Keywords: knowledge, language, philosophy, use, Ranganathan, Wittgenstein

† The author wishes to thank Bruno Nathansohn, of the Instituto Brasileiro de Informação em Ciência e Tecnologia, for the paper's translation into English.

\subsection{Introduction}

In 1930 we find the production of both atomistic and pragmatic conceptions of language. On the one hand, there is the search for a relativistic postulate, and on the other hand there is an essentialist perspective on language, which is placed on the revision of philosophy itself as a practice of the knowing. In other words, "knowledge" is observed under the prism of language; however, this viewpoint originated from two clearly distinct views. We have pragmatic empiricism, which refers to an open plan of the construction of language through ordinary experience, and simultaneously there is neopositivist metaphysics, which searches for rationality based on the idealism of a language without cultural barriers.

In the same decade, the Viennese philosopher Ludwig Wittgenstein, who was the most prominent thinker in the neopositivist vein of the Vienna Circle, was transforming his philosophical proposal, which was originally developed in England. Wittgenstein takes leave from the logisistic reflection of language, and draws closer to a discussion of the multiple characteristics of the production 
of meaning. On the other hand, the Indian mathematician Shiyali Ramamrita Ranganathan started his philosophical work about librarianship when he was in the city of Madras, after he had stayed in the United Kingdom for a period. Far from identifying a parallelism according to the perspectives of each philosopher, it is noticed that there is an exercise of reflecting both on knowledge and on knowledge organization, which comprises respectively the perspectives of both Wittgenstein and Ranganathan in a convergent context.

Acknowledging the relevance of philosophical studies for knowledge organization ( $\mathrm{KO}$ ), we propose, thus, a historic-epistemological study focused on the decade of the 1930s. The pivotal issue is the development of thought aimed at the pragmatics of language in the philosophical scenario of that period. This thought takes ordinary language as a founding element of sense. The idea of usage is recognizable as structural, and only by it is it possible to conceive meaning. Within different perspectives, the Austrian philosopher Wittgenstein and the Indian philosopher Ranganathan discuss epistemological development according to the background of a pragmatics of language.

We approach the production of sense from the concept of use. Ranganathanian pragmatics makes possible withdrawal from the western-modern notion of "knowledge." Since the philosophy of language was established in the ideas of the Indian philosopher, we can think in terms of "ordinary knowledge," taking the practice of organization on the informational level as responsible for a plural notion of epistemology. This positioning draws Ranganathan closer to Wittgensteinian thought, and to the profound development of philosophical studies of ordinary language in the period.

The main objective of this work is to propose an analytical dialogue between the perspectives of Ranganathan and Wittgenstein, on the level of the construction of possibilities of knowing, from the use of language in the 1930s. As specific objectives, we try to define pragmatics as guidance for the construction of knowledge in the 1930s, recognizing the philosophy of language according to Ranganathan, and debating the conditions of the transformation of $\mathrm{KO}$, which is provoked by the pragmatic philosophy of the Indian philosopher.

The method adopted is a panoramic presentation of Wittgenstein, based on the analysis of concepts that conceive of the construction of a grammar inside of a language-using community. Through the panoramic presentation we can identify pressupositions that support effective communication among members of a group, including (for example) a scientific community. As main results, we see the potential for correlation between the development of the philosophy of language in the 1930s, and the construction of an epistemology of KO. Besides the reconstruction of the notion of "knowledge" itself is the issue of information studies, which was started by Ranganathan, as well as possibilities for new meanings for the practice of $\mathrm{KO}$ from the point of view of pragmatics. As a conclusion, we highlight the need for a philosophical review of $\mathrm{KO}$, the recognition of the construction of pragmatics through the twentieth century as a theoretical assumption for $\mathrm{KO}$, and the understanding of a notion of knowledge based on the perspective of usage, according to the pragmatic point of view of language.

\subsection{On the path of language}

Wittgenstein (1979) understands knowledge as an endless walk through contexts and contextualizations, knowledge as action, conferring upon an individual or his social group direct importance in the construction of senses for the world that surrounds it. In this manner, interaction among routine actors emerges from the knowledge of each specific community, because each group of individuals understands the world differently, and recreates this world according to its own perspective. Wittgenstein (1979, 57) worries about language as an enormous risk, and a permanent challenge for the construction of knowledge. He states: "the routine position of contradiction or its position in the ordinary world: this is the philosophical problem."

In this manner, Wittgenstein's pragmatism is a theory that interprets action as a sphere in permanent discontinuity from the plan of routine, finding in the contradiction between the deliberative confrontataion among individuals their subjective perception concerning the social, eminent topic of investigation. This focus, based on the second phase of the Viennese philosopher's theory, points to a wide notion of pragmatics, which has an objective to understand not only the uses of words in language, but also to discuss preocupation with the definition of truth. This focus also recognizes and contextualizes discursive changes within different spheres of communication on the basis of social relations and cultural manifestations, contributing to the explanation of dilemmas of rationality, of scientificity, and of commensurability within knowledge in general, as well as within scientific knowledge, supplying alternatives for the construction of an ethics that discerns alterity within its routine arena.

Such Wittgensteinian pragmatism finds a clear approximation with the Ranganathanian vision about the the process to know, and about the process to organize, and the products of the process to know. When the Indian philosopher debates the range of his philosophical proposals for librarianship, he highlights the need for contingent thought, which is established according to the vision of each culture that takes possession of contents produced as 
a reflection of knowledge, as well as comprising a vision about the need for transformation of the manner of perceiving the ways in which each bibliographic artifact can be seized, its material-symbolic contingence basic to the understanding of such appropriation. What Ranganathan (2009) realizes as a call of books for all is explained by need from a local point of view, recognizing each community, on different levels: of genre, of profit, of class, and of territoriality. Just like that, each group of individuals is included in the democratic vision of access to books: men and women, urban and rural residents.

Because of the contemporary issue about access to knowledge and the emergence of knowledge in the epistemology of information science, there is demand for relevance of approaches to the philosophical reflection about pragmatics. Ludwig Wittgenstein's thought allows a pragmatic-oriented reading, extending the potential of Ranganathian reading, for instance, given the following aspects:

- The viewpoint of a philosophy of information that is based on a sytematic observation of ordinary language;

- The idea of a relationship among science, society, and culture that can be applied within information science;

- The change from the point of view of the scientificity of information science-from the question: "what is science?" which is unfolded in "social science or humanities;" to the question: "when and how are we useful and responsible in the condition of specialists?;" and,

- The debate about the long line of thought in information studies, which is unilaterally structured in a representational philosophy of language.

Perceiving the Indian philosopher's thought as contemporary with these reflections, we can recognize the revolutionary role of Ranganathan in the context of those highlighted questions.

The distinction between essentialism and pragmatism in philosophy is also found in the base practices of KO. It is a matter of what is a deemed backdrop philosophy presented in two directions: representational philosophy, and pragmatics, or pragmatic philosophy, as two scenarios of identity in this area. The notion of a backdrop transmits the idea that those are the two scenarios in which the entirety of the area dedicated to organizing knowledge is always positioned. In the case that we want to observe it from another backdrop, we truly escape from its possible nucleus; that is, studies oriented to knowledge organization, representation, transmission and preservation.

On the one hand, the representational tradition takes language as means and, therefore, as representation. Here the professional who works with the organization of knowledge as a mediator is concerned with the accurate representation of signs, using formal logic, and technology as an ideal model to optimize re-representation and its dynamics; here, meaning is viewed as an ideal representation of a term. On the other hand, the pragmatic tradition presents language as action and therefore as transmission. Here the professional works in the organization of knowledge as interpreter, concerned with contextual transmission of signs, presenting analysis of narratives and of discourses, as a method to understand the possibilities of the organization of knowledge. Meaning is viewed as the use of a term, or its experience. Just like that, pragmatism shares from an anthropological point of view of reality, that is, we can understand the world and its social relations in order to organize its heritage from deconstructing understanding of social uses, which gives meaning to artifacts, and to words.

In this latter tradition, we follow both the "second Wittgenstein" and that presented in Ranganathan, be it a philosopher of librarianship or a theorist of classification. This approach allows us to rethink the construction of the studies of information, mainly in the context of the acknowledgement of language as a unity, not only strategically, but also as a foundation in the area.

\subsection{Ordinary language philosophy in Wittgenstein}

Ludwig Wittgenstein, marked the history of philosophy with his atomistic view about the pragmatic possibilities of comprehension. Wittgenstein tried to present in his second theoretical phase, centrally represented in his Philosophical Investigations, and peripherally by compiled works in the Brown Book and Blue Book among others, that the signification of words is a result of their use in discourse. Here he demonstrates that the ocurrence of terms out of sense is a disenchantment. It is true that this existence is a mistake of language. The use of the term is what confers its meaning.

In the early days of his reflections, however, Wittgenstein believed in an a priori order in the world. Thus, in the beginning of his arguments, the world had a fixed structure (Monk 1995, 126-27). These reflections are theoretical marks of its first discursive phase, defined by the edition of the Tractatus Logico-philosophicus, written between 1917 and 1918, and published in 1921, while the philosopher was fighting in the First World War. The concern with terms and their meanings is, in this work, argued by Wittgenstein, because of the logical foundations of searching for an essence for the uses of language.

As Oliveira (2002, xxiii) stated, "logic creates ... the frame for structuring our knowledge of the pre-existing world." Thus, the logic investigation means "the investigation of the whole regularity; out of the logic everything 
is aleatory, accidental" (2002, xxviii). Bertrand Russell's preface itself in the work corroborates this logic of searching (2002, 2-3): Wittgenstein "is concerned with the necessary conditions for a precise symbolism, e.g., a symbolism in which a phrase means anything that is defined." In other words, "every function of language is to have sense," and it "only satisfies this function in so far as it is approached of ideal language postulated."

The appreciable differences into the direction to other perceptible views in the philosopher's later writings that make that his interpreters divide his works correctly into the first and the second Wittgenstein keep some open elements by the argument on the Tractatus Logico-philosophicus. Thus, to Wittgenstein, philosophy is a "critics of language" (Wittgenstein 2002, 53), and his object is the "clarification" of thought. Philosophy, therefore, in the Wittgensteinian thought, "is not a doctrine, but an activity, in general" (Wittgenstein 2002, 63), an activity of "enlightenment."

At the end of the War, the philosopher faced obstacles to edit his Tractatus, so he left for a small Austrian village, called Trattenbach, where he gave classes for children (Monk 1995, 183-84). During the 1920's, whilst the ideas from the Logic-Pbilosophical Treatise were reverberating, studies in the Viennese Circle confered substantial emphasis on his work from 1929; at this same time, Wittgenstein's book was accepted as a thesis by Moore and Russell (Monk 1995, 250), and the concern about language led the philosopher to construct and edit a dictionary with his students, based on the experience of his classes (Monk 1995, 211). That is, a dictionary based on a "primitive grammar," but not official. It is his approach to pragmaticism. Here, there is a philosophical acknowledgement of how languages can be used by communities under multiple forms, and all of them can be configured as perfectly valid, since they are coherent with the routines of use.

Still in the 1920's, Wittgenstein dictated to a typist his thoughts which were later published as Pbilosophical Observations, the work that made distinctions of different (Monk 1995, 268). Here, Wittgenstein wrote $(2005,57)$ : "grammar proportionates to language the necessary degrees of liberty." It is the principle of a thought that is oriented to the dynamics of language games, to words as action and not as representation; it is dedicated to language game $=$ phenomenology, its description is in the search for social rules that constitute grammar (Wittgenstein 2005, 37).

In the first half of the 1930s, Wittgenstein offered classes to a select group of students. The compilation of material from his classes was recorded in the publications known as Blue Book and Brown Book. These two works expand the pragmatic discussion started in the previous decade by the philosoher, an argument that continued until the philosopher's final writings in the collection of texts entitled On Certainty, written in the last year of his life. In the Blue Book are additional reflections on the notion of "family resemblance," which is a possible substitute for the concept of "essence," presented in the LogicPbilosophical Treatise. While the essence of the "young" Wittgenstein was based on an "anxiety of generalization," according to the familiy similitudes, the philosopher conferred a relativist view on philosophy and its language. In the Brown Book, Wittgenstein intensified his philosophical method, deepening the concept of "language games" (Monk 1995, 304-10).

The Blue Book, which was dictated to the students during the school year 1933-34 in Cambridge, had started from a crucial question (Wittgenstein 1992a, 25): what is the sense of a word? His answers to this question were oriented along a pragmatic order, but it is not formalist as in the work Tractatus Logico-pbilosophicus. That which can "animate the signals," Wittgenstein reveals (1992a, 30), "is its use." In this manner one can (Wittgenstein 1992a, 43), "agree with something that was done or said by means of presenting a way that leads to this action," and in some cases "it means to describe the way which was used;" in others, "it means to describe the way itself, and that is in conformity with certain accepted rules."

The Brown Book, recorded by Wittgenstein's students in the school year 1934-35, will deepen the notion and the method proportioned by language games. For Wittgenstein (1992b, 14), language games are not "incomplete parts of human communication." What governs these language games are the "rules," imagining the term "rule" in its vulgar use, that is, its social use (1992b, 25). Wittgenstein also tries in this work to explore the notion of "primitive language" using more arguments, or "primitive words," that is, as an anthropological viewpoint it apprehends language as a whole in its collective construction, coming upon the concept of "family resemblance".

At the end of 1930s, Wittgenstein prepared the text that would constitute the work that marks what several authors acknowledge as the core of the second phase of his thought, the Pbilosophical Investigations. Nevertheless, because of the Second World War, he could not finish the work (Monk 1995, 369). The philosopher would not testify to the edition of this work, however, it was accessed by readers in a provisory edition that Wittgenstein left in 1949. (Monk 1995, 483)

\subsection{Ranganathan and the "unfinished library"}

Shiyali Ramamrita Ranganathan (1892-1972) was born in the State of Madras (Tâmil Nadu), in India, and may be considered one of the more original thinkers in librarian- 
ship. The Indian philosopher and mathematician placed the library as the center of social and political transformation, such as the Melvil Dewey and Charles Cutter generation did, in the United States and in Europe according to the documentalist school created by Paul Otlet. On the other hand, however, we find glimpses in western reading about the master's thought of Five Laws of Librarianship, mainly because of the difficulty of the reception of the Sanskrit, and the complexity that there is in the context of Indian philosophy as a whole. The Ranganathanian lexicon is fullfiled by hypotexts and allusions to the Vedic and the Indian mysticism.

The experience of Ranganathan's “journey” to the West is crucial for the depth of his knowledge, mainly concerning the complexity of fitting together two distant ways of observing the world, such as the British and the Eastern views. From a logical viewpoint on the manners of thinking and of bringing $\mathrm{KO}$ into the foreground, originating from his education as a mathematician, the philosopher will develop a theoretical work, which will reach the communities' pragmatics in their local contexts of development.

Ranganathan (2009), once nominated to assume responsibility of the University of Madras's library, went to the School of Librarianship at the University of London. The result was a quick and deep process of appropriation of the Anglophone tradition, mainly on the democratic fundamentals of practical elaboration of KO. This event, however, is only a chapter of the long process he experienced in the construction of his philosophy of librarianship. When he returned to Madras, Ranganthan recovered his philosophical mathematically-oriented perspective, and the ways of reflecting are presented in Indian culture. He deductively postulated the laws of librarianship and, in the context of theoretical elaboration, of mystical justification, and of the applied demonstration of his deductions he conceived of an intrinsically pragmatic perspective of librarianship.

The full extent of this perspective is based on the point of view on the other subject, in a posteriori viewpoint of relations between bibliographic artifacts and the users of these artifacts. The concept of "library," under the pragmatic perspective is thus stated from a viewpoint supported by its "use," as announced in his first law, and not by its previous condition as institution, which "keeps" the "knowledge." There is "library" only if there is "use;" there is "book" under the existence of "readers." Besides, both the "library" and the "book" are concepts that only can be thought of in a democratic culture, where access is unlimited. Likewise the appropriate manners of the bibliographic artifacts are the focus of pressupositions of the Anglophone library science philosophical construct, now extended by the conception of the Indian knowledge school.
Generalizing from librarianship in five main deductions, sustained by inductive analysis, are the principles of "facets" of the universe. Thus, Ranganathan (2009) succeeds in using traditionally intertwined philosophical methods by an approach that clearly we would treat today, as incomplete "postmodernism." The first law he created, from which the other laws follow, finds its genesis, according to his narrative, in an "advanced point of time," in 1928, when he got back to India. After his studies in England, he worked in the library, and his exprofessor, Edward B. Ross, had told him: "You want to say, the books are for being used; you want to say that this is your law." From this point starts Ranganathan's library "cosmology" (Ranganathan 2009, 3).

With the emphasis on preservation, the Indian librarianship philosophy, which is represented by a mathematician, is focused on access as a main practice of librarianship. Imprint is stated in accordance with the development of North American thought lines, and of Otletian documentation, and of information science as a whole. Ranganathan $(2009,7)$ demonstrates to us perseverant accordance with the dictum "the books exist for being preserved." This would usurp the first law, which is "the books exist to be used." The Indian reminds us that, before the press, the copy of Mahabharata carried a full life and, in this manner, negligence with the first law was justifiable.

Thus, the focus on accessibility is stated in Ranganathan's "library" (2009), as the place of the institution in the core of a community: "when they saw me to suggest a place in the market street, which went through the heart of the town" (Ranganathan 2009, 11), and the opening in the gradually extended times is initially answered, to what the Indian treats on the first law's "magic of mantra." By this law, the proposed concept of library here only exists in the process of use: "A modern library cannot exist without readers" (Ranganathan 2009, 42).

While the third law points to a wide rhetorical investigation on the possibilities of publicity applied in the library, the fourth law allows us to think about the library as a metaphor of the "logologic town;" to save the reader's time means to create an infrastructure that allows the dynamics of circulation of "connoisseurs" and "knowledge." What counts here are the measures about the spending of time, free access, classified arrangements for bookcases, signaling along the pathways where information can be found, cooperative cataloging, and the construction of a reference service specialized for the user.

This last point would be subdivided into two: fast reference service, and long range reference service. The first would be represented by accessible information kiosks for orienting and instructing the readers, besides giving simple consultations; the second would respond with applied contact between the reader and the reference ser- 
vice, which indicates to an attendance of the librarian until the bookcases with the user (Ranganathan 2009, 226).

On the fifth law, Ranganathan $(2009,263)$ takes the vital principle of libraries to "be an instrument of universal education that gather(s) and diffuses freely all of teaching resources and disseminates knowledge with their supports." The "big library" for Ranganathan $(2009,48)$ is in an inversion of the traditional filia of librarianship thought: the focus still is the friendship of knowledge, but this is not in the books, but in the user, precisely, in the dialogue with the user. Because of that, the librarian shall be "friend, philosopher and leader" for the user: the librarian shall serve the community.

The "big library" focuses on the mantra "education for all," the focus of the second law, a book for each reader: that is, democracy. His "supreme wisdom," affirms Ranganathan $(2009,59)$, is in the art of the war strategy: "The second law will not accept a defeat. At the end, it will win. This is our faith." It would reply by breaking differences of treatment between men and women, between rural men and urban men, between children and adults, between blacks and whites, in every class of workers, searching for affirmation of equality. It is here a clear principle of contextuality, each region responds to a correspondent interest. The "unlimited democracy" defended by the second law responds, finally, to the unrestricted right to teaching and to entertainment (Ranganathan 2009, 92).

In the case of the second law in the Ranganathian thought, we are interested basically in the concept, which is not translatable for the Western world: digvijaya. In medieval India, the term would mean the process of conquest, in the sense of spreading influence on other peoples. In general lines, it would be treated as a military campaign and, by extension, the victory of this campaign took place in a vast territorial space. The digvijaya is responsible for bringing the "democratic novelty announced by the indefatigable Second Law” (Ranganathan 2009, 94).

The librarianship digvijaya only can be thought, to the Indian philosopher, if accepted by the librarianship movement in the United States, in the 19th century, when it became "the land of libraries" (Ranganathan 2009, 95). Its construction would involve a political action centered in multiculturalism. Its discursive project should result in negotiation with the situation of a librarianship legislation liable to make the second law's mantra possible (Ranganathan 2009, 114), "If exists an important lesson, which the history of the Second Law's digvijaya clearly highlights, is the responsibility of the minister of education because of the supplying of books for all" (Ranganathan 2009, 137).

Ranganathan $(2009,49)$ concludes his explanation on the first law calling upon another mantra, since the "Mr. Sri Krishma celebrated words: your right is related to the action, never related to the fruits." Ranganathan's mantra seems to sound repeated, as an eternal and precise bell inside the web, "Never forget that in the libraries, the books are gathered to be used, prepared to be used, kept to be used and offered to be used" (Ranganathan 2009, 41).

On the second law, that is, from its "sketch of the world conquest expedition," a prayer indicates: "Bring the knowledge to whose doors need it/to doors that need it, and to teach everybody to comprehend what is right! Not even the distribution of every land is compared with that form of service" (Ranganathan 2009, 137). The digvijaya, "the march" for the conquest of the world by libraries, according to Ranganathan $(2009,303)$, "is virtually a short history of the movement through libraries in different countries."

\subsection{The books are not for use; the books are the use itself: Ranganathan and Wittgenstein, language and knowledge in 1930s}

The philosophy of language and its deep relevance for information science, as analysed by Blair (1992), finds in Ranganathan a very close perspective of the ordinary language studies in the 1930s, highlighting the Wittgensteinian work. Wittgenstein's concern always was oriented to language problems and their representation communication, such that the philosopher's work gained deeper dimensions for analysis in several areas of investigation in information science. Wittgensteinian inserts are examples undertaken by Novellino (1996) in the study of the transfer of information, and in González de Gómez (1993) about epistemological questions of the representation of knowledge. More than this, in the historic reflection of what we treat today as the area of "philosophy of information" we can identify an extremely fruitful perspective of argumentation between both Ranganathan's and Wittgensteins's pragmatics. One of the stronger questions in this perspective would be in the concept of use, a revolutionary notion for the current contexts of the epistemological reflection of the area.

The notion of use is presented as one of the fundamentals of Wittgenstein's philosophy, and its interaction with the connection between theory and practice in Ranganathanian KO is objective. To Wittgenstein (1979), philosophy must think in a practical form, it must answer the question, what must not be thought to be about an immediate perspective. Thus, it must previously approach ordinary philosophy of primitive languages, and practice also as reflection. His philosophical construction is over against the assumptions of $\mathrm{KO}$ studies as an area of understanding the uses and products of knowledge. In the perspective of Ranganathan (2009), we never can think of the construction of knowledge without observing the practices of appropriation of the users' knowledge: a clear view of his first law. 
Unfolding the notion of "sense" from the question of use, obtained by pragmatics, the category "sense" in Wittgenstein, and in information science resized by a Ranganathanian reading is one of the instances that demands more investigation and exhaustive debate. To Wittgenstein (1979), one of the interrogative formulations, among those that define all the doubt of his philosophical course, is: what does it mean? It will be from this question, from which the philosopher will start his path toward reaching a pragmatic approach.

Likewise, Ranganathan (2009) did not succeed in developing his philosophy before establishing the general deduction based on the notion of use: it is because of the mantra of the first law, and only because of it, that we can imagine the extent of $\mathrm{KO}$ practice. We cannot determine a philosophy of librarianship, in its general character, without an a posteriori viewpoint, which is established because of use. The sense, from the notion of library to the definition of contents of each book, only can be given as the pragmatic strength of the appropriation of knowledge.

Because of the understanding of this point of pragmatic inflection about knowledge, it is possible to comprehend what is behind the first law. The book only can "exist" as the appropriation process of itself. Before the mantra "books are for being used," it is necessary to understand the wide Ranganathanian pragmatic view that the books are use itself. It would be impossible, for the librarian of Madras's philosophical thought, to argue conversely. The concept of book cannot be taken by librarianship without access and appropriation. In other words, to the philosophy of librarianship the concept of "book" does not exist if this is fallen apart from the notion of "use." This places Ranganathan in the sphere of the ordinary language philosophy of the 1930s, demonstrating its similitudes with the second Wittgensteinian view.

\subsection{Conclusion}

We demonstrate how pragmatics, today a common discourse in the epistemology of information science, may receive consideration originating from other demarcations of our thought, highlighting the need for a philosophical revision of KO. That is the case of the Ranganathanian perspective about our practice. His perspective of "use," and his possibility of "signification" concerning the contingent appropriation of knowledge are contemporary with important philosophical analysis, like those undertaken by Wittgenstein.

An important critical revision between the expression "organization of knowledge," and the notion of "scientific knowledge," is highlighted, in this last case, to think of the core of reflection of information science in its epistemological construction in the 20th century. It is notorious that the concept of "organization of knowledge" dates back to the Anglophone tradition of library science in the 19th century. It reflects, in a certain measure, a typical way of knowing, and a way of conceptualizing knowledge in the $18^{\text {th }}$ century, based on positivism and in an empirical view of the exercise of human reflection.

If the scientific weight of the term "knowledge" is withdrawn, we notice that, according to both pragmatics and Wittgenstein's thought, Ranganathan demonstrates that the idea behind the process of knowing pervades all kinds of ordinary knowledge. If knowledge is blurred with empirical science, after the 18th century, Wittgensteinian thought and Ranganathanian philosophy openly question the multiplicity of knowledge, with the pragmatics of the $18^{\text {th }}$ century, and not the logicist unity of knowledge.

Likewise, the expression "organization of ordinary knowledge" responds through a philosophic-historic argument: if we think in terms of "organization of knowledge," we would tend to approach fundamentally the 20th century. That is the moment when this concept emerged, and, in fact, it is based on the discursive scenery of information science. Conversely, a significant issue to think of organization as the foundational concept in Ranganathan, would be approached closer to the idea of organization of ordinary knowledge. The use of the term ordinary knowledge completes this justification: we have here the idea of knowledge as a socially constructed practice, and based on the diversity of communities, and on the compexity of differences. It is not only a means, like the case of the academic context. It is a kind of knowledge, which is in the process of the use of language, which is experienced by each group of individuals in different spaces: only from this perspective could we think about an epistemology of the area, today predicated as originating from information.

\section{References}

Blair, D.C. 1992. Information retrieval and the philosophy of language. The computer journal 35: 200-7.

González de Gómez, Maria Nélida. 1993. A Representação do conhecimento e o conhecimento da representação: algumas questões epistemológicas. Ciência da informação 22: 217-22.

Monk, Ray. 1995. Wittgenstein: o dever do gênio. Translated by Carlos Afonso Malferrari. São Paulo: Cia das Letras.

Novellino, Maria Sallet. 1996. A teoria da ação comunicativa e a representação da informação. Informare: cadernos do Programa de Pós-Graduação em Ciência da Informação 2 no. 2: 73-9. 
Oliveira, Tiago de. 2002. Alguns comentários sobre o Tractatus. In Wittgenstein, Ludwig, Tratado lógico filosófico; Investigações filosóficas. Lisboa: Fundação Calouste Gulbenkian, pp. XI -XXXII.

Ranganathan, Shyiali Ramamrita. 2009. As Cinco leis da Biblioteconomia. Brasília: Briquet de Lemos.

Russel, Bertrand. 2002. Prefácio. In Wittgenstein, Ludwig, Tratado lógico filosófico; Investigações filosóficas. Lisboa: Fundação Calouste Gulbenkian, pp. 1-24.

Wittgenstein, Ludwig. 1979. Investigaçoes filosóficas. São Paulo: Abril Cultural.
Wittgenstein, Ludwig. 1992a. O livro azul. Lisboa: Edições 70.

Wittgenstein, Ludwig. 1992b. O livro castanho. Rio de Janeiro: Edições 70.

Wittgenstein, Ludwig. 2002. Tratado lógico filosófico; Investigações filosóficas. Lisboa: Fundação Calouste Gulbenkian.

Wittgenstein, Ludwig. 2005. Observações filosóficas. São Paulo: Loyola. 